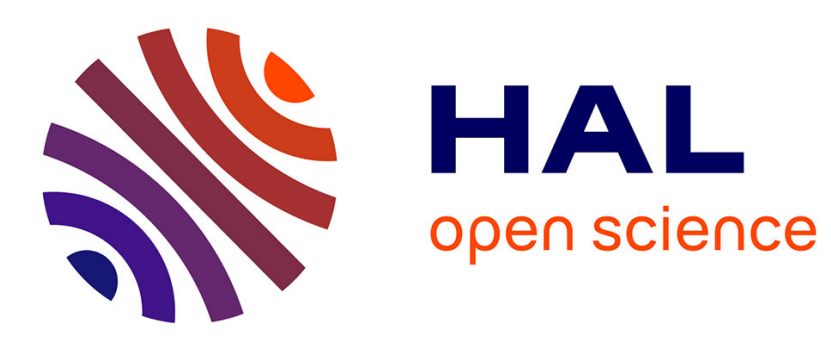

\title{
Genetic and species-level biodiversity patterns are linked by demography and ecological opportunity
}

Chloé Schmidt, Stéphane Dray, Colin J Garroway

\section{To cite this version:}

Chloé Schmidt, Stéphane Dray, Colin J Garroway. Genetic and species-level biodiversity patterns are linked by demography and ecological opportunity. Evolution - International Journal of Organic Evolution, 2022, 76, 10.1111/evo.14407 . hal-03447096

\section{HAL Id: hal-03447096 \\ https://univ-lyon1.hal.science/hal-03447096}

Submitted on 24 Nov 2021

HAL is a multi-disciplinary open access archive for the deposit and dissemination of scientific research documents, whether they are published or not. The documents may come from teaching and research institutions in France or abroad, or from public or private research centers.
L'archive ouverte pluridisciplinaire HAL, est destinée au dépôt et à la diffusion de documents scientifiques de niveau recherche, publiés ou non, émanant des établissements d'enseignement et de recherche français ou étrangers, des laboratoires publics ou privés. 


\section{Title: Genetic and species-level biodiversity patterns are linked by}

2 demography and ecological opportunity

3

Running title: Geography of nuclear genetic diversity

Authors: Chloé Schmidt ${ }^{* *}$, Stéphane Dray ${ }^{2}$, Colin J. Garroway ${ }^{1 *}$

\section{Affiliations:}

'Department of Biological Sciences, 50 Sifton Rd, University of Manitoba, Winnipeg, Manitoba R3T 2N2 Canada

${ }^{2}$ Univ Lyon, Université Claude Bernard Lyon 1, CNRS, Laboratoire de Biométrie et Biologie Evolutive, F-69100, Villeurbanne, France

*Correspondence to:

Chloé Schmidt

Department of Biological Sciences

50 Sifton Rd

University of Manitoba

Winnipeg, MB R3T 2N2

email: schmid46@myumanitoba.ca

Colin J Garroway

Department of Biological Sciences

50 Sifton Rd

University of Manitoba

Winnipeg, MB R3T 2N2

email: colin.garroway@umanitoba.ca 
31 Abstract: The processes that give rise to species richness gradients are not well understood, but

32 may be linked to resource-based limits on the number of species a region can support. Ecological

33 limits placed on regional species richness would also limit population sizes, suggesting that these

34 processes could also generate genetic diversity gradients. If true, we might better understand how

35 broad-scale biodiversity patterns are formed by identifying the common causes of genetic

36 diversity and species richness. We develop a hypothetical framework based on the consequences

37 of regional variation in ecological limits to simultaneously explain spatial patterns of species

38 richness and neutral genetic diversity. Repurposing raw genotypic data spanning 38 mammal

39 species sampled across 801 sites in North America, we show that estimates of genome-wide

40 genetic diversity and species richness share spatial structure. Notably, species richness hotspots

41 tend to harbor lower levels of within-species genetic variation. A structural equation model

42 encompassing eco-evolutionary processes related to resource availability, habitat heterogeneity,

43 and human disturbance explained $78 \%$ of variation in genetic diversity and $74 \%$ of the variation

44 in species richness. These results suggest we can infer broad-scale patterns of species and genetic

45 diversity using two simple environmental measures of resource availability and ecological

46 opportunity.

48 Keywords: more individuals hypothesis, heterogeneity, Anthropocene, latitudinal diversity

49 gradient, carrying capacity, macroecology, macrogenetics 


\section{Introduction}

51 Genetic diversity and species richness are the most fundamental levels of biodiversity because

52 they reflect within- and across-species contributions to ecosystem functioning (Oliver et al.

53 2015; Des Roches et al. 2021b). Genetic diversity underlies a population's capacity to adapt in

54 response to environmental change, and species richness enhances ecosystem resiliency to

55 perturbation. If we are to manage the current high rates of biodiversity loss, we need to better

56 understand how patterns of biodiversity are produced and how they interact across levels of

57 biological organization. Patterns of species richness are well-described, but because several

58 independent processes are capable of generating these patterns, their origins remain puzzling. We

59 know less about multi-species patterns of genetic diversity. However, there is good reason to

60 think that the processes forming patterns of species richness could simultaneously produce

61 spatial patterns in neutral genetic diversity (Vellend 2005; Evanno et al. 2009). This is because

62 spatial variation in neutral genetic diversity should reflect how local population-level

63 demographic and evolutionary processes interact with environments to produce species richness

64 gradients. If true, we may be able to infer processes underlying biodiversity patterns at both

65 genetic and species levels by attempting to understand their common causes. The accumulation

66 of open data now allows us to tackle these types of questions by repurposing and synthesizing

67 publicly archived raw data (e.g., Leigh et al. in press; Miraldo et al. 2016; Manel et al. 2020;

68 Schmidt et al. 2020a; Theodoridis et al. 2020; Schmidt and Garroway 2021). Here we produce a

69 continental map of spatial variation in neutral nuclear genetic diversity for North American

70 mammals, show that genetic diversity and species richness covary spatially and are negatively

71 correlated, and find empirical support suggesting that measures of resource availability and 
72 heterogeneity predict both genetic diversity and species richness patterns through their effects on

73 demography.

75 We developed a conceptual framework to explain how genetic diversity and species richness

76 patterns could emerge from common causes. This framework extends predictions from well-

77 supported hypotheses for species richness patterns to the population genetic level. Hypotheses

78 for species richness gradients fall into three general categories related to evolutionary time,

79 evolutionary rates, and ecological limits (Mittelbach et al. 2007; Worm and Tittensor 2018;

80 Pontarp et al. 2019). We focus on ecological limits hypotheses-these posit that variation in

81 resource availability limits the number of species able to coexist in a particular area (Rabosky

82 and Hurlbert 2015). Here the speciation, extinction, and colonization dynamics of species are

83 analogous to the birth, death, and immigration dynamics that set carrying capacities at the

84 population level. Simulations suggest multiple hypotheses can produce species richness gradients

85 (Etienne et al. 2019), but the preponderance of theory suggests that ecological limits produce the

86 strongest and most stable gradients (Vellend 2005; Worm and Tittensor 2018; Etienne et al.

87 2019). There is also good empirical support for the likely importance of ecological limits in the

88 formation of species richness patterns (reviewed in Rabosky and Hurlbert 2015; Brodie 2019).

89 We thus considered ecological limits hypotheses as parsimonious starting expectations when

90 exploring the causes of biodiversity patterns (Etienne et al. 2019).

91

92 It is relatively straightforward to extend the consequences of ecological limits on community size

93 to the population genetic level. If environments limit the number of supportable species, they

94 must also limit the population sizes of species, and therefore affect the strength of genetic drift. 
95 The first ecological limits hypothesis we consider is the more individuals hypothesis (Wright

96 1983). In terms of community composition, the more individuals hypothesis suggests that

97 resource availability imposes an upper limit on the number of individuals, and as a consequence,

98 the number of species an area can support (Currie 1991; Rabosky and Hurlbert 2015; Storch et

99 al. 2018). Diversity tends to increase with the number of individuals in an assemblage both in

100 terms of genetic diversity within populations and the number of species in a community (Kimura

101 1983; Hubbell 2001). Thus, the more individuals hypothesis predicts neutral genetic diversity

102 and species richness will be positively correlated and increase with resource availability (Fig. 1).

103 The second ecological limits hypothesis we consider pertains to environmental heterogeneity,

104 which includes variation in resources, habitat types, and habitat complexity (Stein et al. 2014).

105 Here we assume heterogeneity equates to niche availability. The idea of area-heterogeneity

106 trade-offs suggests that heterogeneous areas can support richer communities of more specialized

107 species, but these species should tend to have smaller population sizes because resources and

108 species are divided among niches (Kadmon and Allouche 2007; Allouche et al. 2012). Local

109 adaptation, and subsequently specialization, can also occur within and across species distributed

110 across heterogeneous environments. As increasingly specialized populations diverge, genetic

111 variation would be partitioned among locally adapted populations that may eventually no longer

112 interbreed. Compared to larger populations, these smaller populations would also more rapidly

113 lose genetic diversity due to genetic drift. If this were the case, we expect environmental

114 heterogeneity would be positively associated with species richness and negatively associated

115 with neutral genetic diversity (Fig. 1).

116 Contemporary rapid environmental change also affects biodiversity patterns, yet it is not

117 typically modelled in a way that makes it comparable to historical processes acting over long 
118 periods. A major contemporary ecological limit on diversity is human land transformation.

119 Human activities such as urbanization reduce the amount of habitat available to wild populations

120 (McKinney 2006; Grimm et al. 2008) with consequences at genetic and species levels (Ceballos

121 et al. 2015; WWF 2018; Leigh et al. 2019; Schmidt et al. 2020a). Habitat loss, fragmentation,

122 and homogenization resulting from human land use alters resource and niche availability, thus

123 processes associated with ecological limits should play out in populations and communities of

124 urban wildlife. By reducing habitable area and resource heterogeneity, we predicted that the

125 effects of urbanization for mammals should also cause species richness and genetic diversity to

126 decrease in more heavily disturbed areas (Fig. 1).

128 The effects of resource availability and heterogeneity are not mutually exclusive, and in our

129 framework they can act in concert to produce biodiversity patterns. The links among our

130 hypotheses and their predictions are diagrammed in full in Figure 1. We jointly model both

131 hypotheses with a method that allows us to assess their relative importance for shaping genetic

132 diversity and species richness. Our predictions for the ways resource availability and

133 heterogeneity interact are consistent with previous work on species richness in North American

134 mammals (Kerr and Packer 1997), where heterogeneity becomes a more important determinant

135 of species richness as resource availability increases. If our model successfully captures known

136 relationships between species richness and environments, and genetic diversity behaves in the

137 ways we predict, we will have strong empirical evidence supporting the contention that

138 continental patterns of neutral genetic diversity and species richness are both are in part governed

139 by ecological limits. 
141 Our specific objectives were threefold. Because biogeographic patterns of neutral nuclear genetic

142 diversity have not yet been mapped, we first produced a continental map of spatial patterns of

143 genetic diversity in North American mammals. To do this we repurposed publicly archived, raw,

144 neutral nuclear genetic data spanning 38 species and $>34,000$ individuals at 801 sample sites in

145 the United States and Canada. We then tested the degree to which patterns of genetic diversity

146 matched those of species richness. Having established shared patterns of spatial variation, we

147 then tested our proposed conceptual model based on ecological limits hypotheses where genetic

148 diversity and species richness are caused by common environmental factors (Fig. 1). We tested

149 our hypothetical model using structural equation modelling (SEM), a modelling framework that

150 fits hypothesis networks by accommodating multiple predictor and response variables. Our

151 approach (Fig. 2) allowed us to assess the relative importance of both hypotheses and the effects

152 of contemporary environmental change while accounting for species-level variation using

153 hierarchical models.

\section{Methods}

\section{Biodiversity data}

157 Genetic diversity. We used raw genotypic data compiled by Schmidt et al. (2020a,b). This data

158 set is comprised of repurposed raw microsatellite data from 34,841 individuals from 38

159 mammalian species sampled at 801 sites in the United States and Canada. With it we could

160 consistently calculate measures of gene diversity (Nei 1973) and population-specific F ST $_{\text {across }}$

161 sites (Weir and Goudet 2017). See Table 1 for a summary of the dataset. Microsatellite markers

162 estimate genome-wide diversity well (e.g., microsatellite and genome-wide diversity are

163 correlated at $\mathrm{R}^{2} \sim 0.83$; Mittell et al. 2015). They are commonly used in wildlife population 
164 genetic studies because they are cost-effective and do not require a reference genome, which

165 allowed us to maximize sample size. Detailed methods for assembling this dataset can be found

166 in (Schmidt et al. 2020a). Briefly, we performed a systematic search for species names of native

167 North American mammals with keywords "microsat*", "single tandem*", "short tandem*", and

168 "str" using the dataone R package, which interfaces with the DataONE platform to search online

169 open data repositories (Jones et al. 2017). We discarded search results that did not meet our

170 criteria for inclusion and removed results where study design may have influenced genetic

171 diversity. For example, we excluded non-neutral data and samples taken after a recent

172 bottleneck, translocations, managed or captive populations, or island populations. We

173 additionally removed populations with fewer than 5 individuals sampled. Gene diversity

174 estimates the richness and evenness of alleles in a population, and we used it here as our metric

175 for genetic diversity because it is minimally affected by sample size (Charlesworth and

176 Charlesworth 2010) (Fig. S1). Sample sites are treated as point locations.

177 Species richness. We downloaded range maps for terrestrial mammals native to North America

178 from the IUCN Red List database (IUCN 2019). We filtered these maps to retain ranges for

179 extant, native, resident, mainland species in $\mathrm{R}$ version 4.0.1 ( $\mathrm{R}$ Core Team 2020). To generate a

180 map of species richness coincident with genetic sample sites, we estimated species richness by

181 summing the number of ranges overlapping each site.

\section{Maps and spatial variation partitioning}

184 Genetic diversity and species richness maps. Our first step was to map spatial patterns in genetic

185 diversity. We accomplished this using distance-based Moran's eigenvector maps (MEMs) in the

186 package adespatial (Dray et al. 2017). MEMs detect spatial patterns in data using a matrix of 
187 distances between sites — a neighbor matrix — whose eigenvalues are proportional to Moran's I

188 index of spatial autocorrelation (Borcard and Legendre 2002; Borcard et al. 2004; Dray et al.

189 2006). MEMs are spatial eigenvectors that represent relationships between sites at all spatial

190 scales detectable by the sampling scheme. Multiple MEMs can be included in linear models to

191 identify spatial patterns in data because they are orthogonal. They are appropriate for use in

192 genetics because Moran's I is a direct analog of Malécot's estimator of spatial autocorrelation of

193 allele frequencies (Malécot 1955; Epperson 2005) which accurately summarizes neutral variation

194 in gene flow and allele frequencies (e.g., Sokal and Oden 1978; Epperson 2005). Distance-based

195 MEM analysis produces $n-1$ MEMs ( $n$ being the number of sample sites), but only eigenvectors

196 corresponding to positive spatial autocorrelation are used. MEMs are ordered according to

197 spatial scale explained, with the first eigenvector explaining the broadest autocorrelation pattern.

198 We used linear regressions and the forward selection procedure described in (Blanchet et al.

199 2008) to select two sets of MEMs: one describing spatial patterns in genetic diversity and the

200 other describing species richness. Thirteen MEMs, ranging from broad to fine scales, explained

201 important spatial variation in gene diversity. Forty-three MEMs were important predictors of

202 species richness, and 8 of these patterns were shared by genetic diversity (significant MEMs are

203 listed in Fig. S3).

204 To restrict ourselves to broad spatial patterns, we focused on genetic and species MEMs with

205 Moran's I values $>0.25$. We fit individual linear regression models for species richness and

206 genetic diversity with corresponding broad-scale MEMs as covariates and plotted model

207 predicted values representing spatial patterns on maps of North America (Fig. 3). These MEMs

208 describe the broadest-scale spatial patterns at both levels of diversity. By using values of genetic

209 diversity and species richness described by these MEMs, we can visualize pure spatial variation 
210 at the continental scale without local spatial patterns that may be due to environmental

211 idiosyncrasies, and without considering non-spatial variation in genetic diversity. We also

212 provided maps of raw genetic diversity and species richness values in Figure S2.

213

214 Variation partitioning. We next quantified the extent to which genetic diversity and species

215 richness covary spatially. Because MEMs for species richness and genetic diversity were

216 computed from the same set of coordinates, they were directly comparable. This allowed us to

217 identify shared spatial MEMs. We used linear regressions and variance partitioning to determine

218 what fraction of the total variation in species richness and genetic diversity could be attributed

219 to: (1) non-spatial variation, (2) non-shared spatial variation, and (3) shared spatial variation. We

220 partitioned variation as follows:

$$
\begin{gathered}
\mathrm{y}_{S R} \sim \alpha+\beta_{1 S}\left(\mathrm{MEM}_{1 S}\right)+\beta_{2 S}\left(\mathrm{MEM}_{2 \mathrm{~S}}\right)+\cdots+\beta_{43 S}\left(\mathrm{MEM}_{43 S}\right)+\epsilon \\
\mathrm{y}_{G D} \sim \alpha+\beta_{1 G}\left(\mathrm{MEM}_{1 G}\right)+\beta_{2 G}\left(\mathrm{MEM}_{2 \mathrm{G}}\right)+\cdots+\beta_{13 G}\left(\mathrm{MEM}_{13 G}\right)+\epsilon
\end{gathered}
$$

223 where $\alpha$ is the grand mean, and $\mathrm{ySR}_{\mathrm{SR}}$ and $\mathrm{y}_{\mathrm{GD}}$ are species richness and genetic diversity at sites.

$224 \mathrm{MEM}_{S}$ and $\mathrm{MEM}_{G}$ refer to the set of MEMs explaining spatial variation in species richness (43

225 MEMs) and genetic diversity (13 MEMs), respectively, and $\beta$ s are their slopes. The coefficients

226 of variation $\left(\mathrm{R}^{2}\right)$ for these models give us the proportion of variation in each response variable

227 attributable to spatial variation. Subtracting these values from 1 gives the amount of non-spatial

228 variation.

229 To determine the amount of shared variation, we used the set of 8 MEMs shared between species

230 richness and genetic diversity $\left(\mathrm{MEM}_{\mathrm{SG}}\right)$ as predictors in the regressions below:

$$
\mathrm{y}_{S R} \sim \alpha+\beta_{1 S G}\left(\mathrm{MEM}_{1 S G}\right)+\beta_{2 S G}\left(\mathrm{MEM}_{2 \mathrm{SG}}\right)+\cdots+\beta_{8 S G}\left(\mathrm{MEM}_{8 S G}\right)+\epsilon
$$




$$
\mathrm{y}_{G D} \sim \alpha+\beta_{1 S G}\left(\mathrm{MEM}_{1 S G}\right)+\beta_{2 S G}\left(\mathrm{MEM}_{2 S G}\right)+\cdots+\beta_{8 S G}\left(\mathrm{MEM}_{8 S G}\right)+\epsilon
$$

$233 \mathrm{R}^{2}$ values from these models estimate the proportion of variation in genetic diversity and species

234 richness explained by shared spatial variation. Subtracting these values from the total spatial

235 variation in species richness and genetic diversity gives the proportion of non-shared spatial 236 variation.

\section{Structural equation modeling}

239 Population size data. The more individuals hypothesis is most applicable at broad spatial scales,

240 and when considering the total number of individuals that comprise a species (Storch et al.

241 2018). In place of census sizes for the species in our dataset, which are not consistently available,

242 we craft our hypothesis around species' long-term effective population sizes. The effective

243 population size is a concept defined in population genetics as the number of individuals in an

244 idealized population that experiences the same rate of genetic drift as the real population

245 (Charlesworth and Charlesworth 2010). Populations lose genetic diversity to drift at a rate

246 inversely proportional to the effective population size. Body size is routinely used as a proxy for

247 long-term effective population size at the species level (Frankham 1996; Corbett-Detig et al.

248 2015; Mackintosh et al. 2019; Buffalo 2021). Large bodied species that tend to have long

249 lifespans and produce few offspring generally have smaller effective population sizes than small,

250 fecund, short-lived species (Romiguier et al. 2014; Mackintosh et al. 2019). Thus body size

251 measured at the species level is an imperfect, but nevertheless useful substitution for census size.

252 We recorded adult body mass (g) for each species in our genetic dataset from the PanTHERIA

253 database (Jones et al. 2009) and log-transformed values before analysis. There were no obvious

254 outliers in these data. 
Environmental variables. We used potential evapotranspiration as a surrogate for total ecosystem

256 resource availability (Currie 1991; Rabosky and Hurlbert 2015). Potential evapotranspiration is

257 an indicator of atmospheric energy availability and is one of the strongest environmental

258 correlates of species richness in North American mammals (Currie 1991; Kreft and Jetz 2007;

259 Fisher et al. 2011; Jiménez-Alfaro et al. 2016). As we predict, at the species level, that resource

260 availability across a range sets the long-term effective population size, we estimated mean range-

261 wide potential evapotranspiration (mm/yr) using annual data from 1970-2000 available via the

262 CGIAR Consortium for Spatial Information (Trabucco and Zomer 2019). For comparison, we

263 also measured mean range-wide actual evapotranspiration, an alternative measure of resource

264 availability, and present those results in the Supplementary Information.

265 We quantified heterogeneity and niche availability using a $250 \mathrm{~m}$ resolution map of land cover

266 types in North America (CEC et al. 2010). This map includes 19 land cover categories based on

267 satellite imagery collected in 2010 with multiple categories of forest, shrubland, grassland, polar

268 habitat types, wetland, cropland, barren land, built up land, and open water. Because the

269 heterogeneity hypothesis suggests species specialize on different resources within their range, we

270 quantified heterogeneity at sites rather than at the species level. We measured heterogeneity

271 using Simpson's diversity index. To assess scale dependence, we calculated Simpson's index

272 within four buffer zones around each site: 5000, 20000, 50000, and $100000 \mathrm{~km}^{2}$. Lastly, we

273 quantified human disturbance at each site using human population density (CIESIN 2016)

274 measured within a $10 \mathrm{~km}$ buffer following Schmidt et al. (2020a).

275 Analysis. Structural equation modeling accommodates multiple dependent and independent

276 variables in a model network, and directional paths connecting variables represent causal 
277 relationships. The strengths of direct paths are regression coefficients (Shipley 2016), and

278 indirect effects can be quantified by multiplying coefficients along paths of direct effects.

279 We constructed a graph of our conceptual model laid out in the introduction (Fig. 1), which we

280 then translated into a network of three linear models for body size, species richness, and genetic

281 diversity. In it, body size is predicted by resource availability, and species richness and genetic

282 diversity are each predicted by body size, heterogeneity, and human disturbance (Fig. 4a). We fit

283 structural equation models using piecewiseSEM in R (Lefcheck 2016; Lefcheck et al. 2019)

284 because this package accommodates complex model structures. We used a linear mixed-effects

285 model with a random intercept for species to account for species-level variation in genetic

286 diversity. PiecewiseSEM fits hierarchical models using the lme4 package (Bates et al. 2015).

287 Body size and species richness models were initially fit as linear regressions, but residuals from

288 both models were spatially autocorrelated at broad scales. We refit these regressions using

289 simultaneous autoregressive models in spatialreg (Bivand et al. 2013) and this successfully

290 removed spatial autocorrelation from the residuals. All variables were scaled and centered before

291 analysis to obtain standardized regression coefficients, allowing us to compare the strength of

292 relationships and the relative support for hypotheses across genetic and species levels.

293 Our model includes variables measured at the site level (genetic diversity, species richness,

294 heterogeneity, and human disturbance) and species level (body size, resource availability; Fig.

295 2). This hierarchical data structure introduces spurious correlations between variables sampled at

296 different levels that we know are not causal. For example, regressing human disturbance at sites

297 on species body size would estimate an artefactual experiment (the size of species researchers

298 choose to sample near cities) — not the effects of disturbance on body size. We can account for

299 these known non-causal relationships by allowing variables to have correlated errors (Lefcheck 
2016). Correlated errors indicate that a relationship exists between variables, but allow the

301 direction of causality to be ambiguous: both could be caused by another factor not included in

302 the model (e.g., researcher species choice). We specified correlated errors between body size and

303 human population density, and body size and heterogeneity.

304 The conceptual model is evaluated by testing whether additional links are needed between

305 variables to make the proposed causal structure more consistent with the data. In piecewiseSEM,

306 missing links are tested using tests of directed separation (Shipley 2016), where the null

307 hypothesis is that two variables are independent conditional on other predictors in the model. A $p$

308 value for the model network is obtained by testing Fisher's C calculated from the $p$ values

309 summed across directed separation tests (Lefcheck 2016; Shipley 2016). A model-wide $p<0.05$

310 means the causal structure is not a good fit to the data and additional links are needed to resolve

311 dependencies. If $p>0.05$, the model is considered acceptable because we fail to reject our causal

312 structure. This means that although we start with a focus on our conceptual model, the data can

313 suggest the addition or removal of links and our hypotheses can be updated for future testing

314 with new data.

315 We assessed model fit using $\mathrm{R}^{2}$ values for each response variable in the model network. For

316 genetic diversity, we used marginal $\mathrm{R}^{2}\left(\mathrm{R}^{2} \mathrm{~m}\right)$ which measures the total variation explained by

317 fixed effects, and conditional $\mathrm{R}^{2}\left(\mathrm{R}_{\mathrm{c}}^{2}\right)$ which is the variation explained by both fixed and random

318 effects. For spatial body size and species richness regressions, we report Nagelkerke pseudo- $\mathrm{R}^{2}$.

320 Effect of heterogeneity on population divergence

321 After detecting a negative effect of heterogeneity on intraspecific genetic diversity in our

322 structural equation model, we performed a post hoc analysis to test whether environmental 
323 heterogeneity also caused greater population differentiation within species. To test for

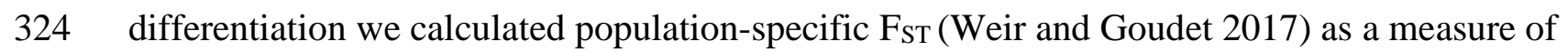

325 genetic divergence using the hierfstat package (Goudet and Jombart 2015). Population-specific

326 F 3 can be interpreted as a relative estimate of the time since a population has diverged from a

327 common ancestor. This metric required at least 2 sampled populations in the original studies to

328 estimate, and due to this constraint 16 sites were excluded from this analysis. We controlled for

329 isolation-by-distance by including MEMs significantly related to $\mathrm{F}_{\mathrm{ST}}$ to account for spatial

330 structure. We scaled and centered all variables, then used a linear mixed model controlling for

331 species differences by including it as a random effect.

\section{Results}

334 Spatial patterns in genetic diversity and species richness

335 There was no obvious relationship between latitude and nuclear genetic diversity (Fig. 3).

336 Similar to patterns of species richness, a longitudinal gradient in genetic diversity was the

337 dominant pattern for North American mammals - however, it appears regions with high species

338 richness have lower genetic diversity. We detected spatial patterns at genetic and species levels

339 of diversity. Sixty-five percent of the total variation in species richness and $24 \%$ of variation in

340 genetic diversity was spatially structured (Fig. 3). Variance partitioning suggested that $85 \%$ of

341 the total spatial variation in genetic diversity, and $32 \%$ of spatial variation in species richness

342 was accounted for by spatial patterns shared at both levels of diversity. This shared variation

343 implies that, to an extent, neutral genetic diversity and species richness are simultaneously

344 shaped by spatially structured environmental factors, and these shared processes account for

345 most of the spatial variation in genetic diversity. 
347 Joint environmental causes of genetic diversity and species richness

348 We present results from the model using a $5000 \mathrm{~km}^{2}$ heterogeneity buffer in the main text.

349 Results from wider heterogeneity buffers can be found in SI Tables S1-S4. Our conceptual

350 model, updated according to tests of directed separation, fit the data well (SEM $p=0.33$, Fisher's

$351 \mathrm{C}=2.245$; Fig. 4, Table S1). Note that for structural equation models, $p>0.05$ indicates that we

352 fail to reject our model. There was no residual spatial autocorrelation in body size and species

353 richness model residuals, and genetic diversity model residuals were spatially autocorrelated at

354 local scales (genetic diversity Moran’s I = 0.01). These Moran's I values indicate very weak

355 spatial structure in the data, and so we decided not to integrate it into our model. Positive spatial

356 autocorrelation at such short distances is likely an artifact of irregular site locations and the

357 hierarchical nature of the data. A lack of strong spatial autocorrelation in the model residuals

358 suggests that the spatial structure of the diversity data was well captured by our model's

359 environmental covariates (Fig. S3). All predicted links in our conceptual model were supported

360 except that between body size and species richness (Fig. 4). Tests of directed separation

361 suggested additional direct links from resource availability to species richness, and genetic

362 diversity to species richness (Fig. 4). Effects of heterogeneity on genetic diversity were not

363 detectable at broader scales (Tables S2-S4). These relationships were consistent using actual

364 evapotranspiration as an alternative measure of resource availability (Table S5).

365 Resource availability, heterogeneity, and human disturbance, acting both directly and indirectly

366 through species population size, explained $20 \%$ of the variation in genetic diversity. The species-

367 level variation explained by the random effect brought the total variation in genetic diversity

368 explained by our model to $78 \%$. The same model explained $74 \%$ of the variation in species 
richness. Genetic diversity was strongly negatively related to body size. The direct effects of

370 resource heterogeneity on species richness and genetic diversity were of similar magnitude, and

371 directions of effects were as expected if processes associated with greater resource heterogeneity

372 reduce population sizes, lead to increased genetic drift, and facilitate local adaptation and

373 coexistence (Fig. 4, Table S1). However, because gene diversity is not a measure of divergence,

374 we additionally tested whether environmental heterogeneity predicted evolutionary divergence at

375 the population level. Heterogeneity was positively related to genetic divergence, but the effect

376 was not significant $(\beta=0.06 \pm 0.04 \mathrm{SE})$. Finally, human disturbance negatively affected both

377 species richness and genetic diversity, but its effects were stronger for genetic diversity (Fig. 4,

378 Table S1).

380 Discussion

381 We found striking continental spatial gradients in nuclear genetic diversity, and show that these

382 patterns are negatively correlated with patterns of species richness in North America (Simpson

383 1964) (Fig. 3). A considerable portion of the variation in genetic diversity and species richness

384 patterns could be explained by just three environmental factors: resource availability, resource

385 heterogeneity, and human disturbance. This is strong empirical evidence suggesting that genetic

386 diversity and species richness patterns emerge, in part, from the same environmental processes.

388 Both our maps and our structural equation model suggest that resource availability and

389 heterogeneity interact to produce biodiversity patterns at genetic and species levels. In North

390 America, the threshold where environmental heterogeneity presumably becomes a more

391 important determinant of species richness than resource availability lies roughly along the US- 
392 Canada border where potential evapotranspiration reaches $~ 1000$ mm/yr (Kerr and Packer 1997).

393 Near this threshold is also where we see longitudinal patterns of genetic diversity emerge.

394 Although the negative correlation between spatial patterns of genetic diversity and species

395 richness is most apparent in species richness hotspots (particularly in the southwest), structural

396 equation modeling incorporating both hypotheses gives us a more nuanced view of the

397 connections between these patterns. Indeed, effects related to resource availability and

398 heterogeneity were of similar magnitude (Fig. 4). Population size and genetic diversity increased

399 with resource availability, and though the link between species' long-term effective population

400 sizes and species richness was unsupported, species richness also increased with resource

401 availability. Moreover, we detected a positive relationship between genetic diversity and species

402 richness as predicted if population and community size increase with resource availability. It

403 may be that effective population size, measured using species body size, is too coarse an

404 indicator of census population size to detect an effect on species richness at sites — if so, site-

405 level measures of genetic diversity could be a better indicator of local population sizes.

407 Our results suggest that once a minimum energy threshold is reached, populations can afford to 408 specialize in heterogeneous environments while maintaining viable population sizes. In this way,

409 the interplay between ecological limits and ecological opportunity simultaneously produces

410 biogeographic patterns in genetic diversity and species richness. This interpretation of our results

411 assumes that an environmentally set equilibrium between speciation, immigration and extinction

412 has been reached. There is good evidence for this in North American mammals, where

413 diversification rates have slowed as diversity increased (Alroy 2009; Brodie 2019). However, the

414 specific ways environments shape nuclear genetic- and species-level diversity will likely differ 
415 across taxa and regions depending on whether or not they have reached equilibrium (e.g.,

416 Schmidt et al. 2021). Though we measure contemporary genetic diversity, historical variation in

417 resource availability and heterogeneity likely contribute to the patterns we detect because they

418 reflect whether populations have experienced large contractions in the recent past (Hewitt 2000).

419 However, in the past when communities may not have been at equilibrium, it seems likely that

420 other processes could have been the predominant drivers of biodiversity patterns. Indeed,

421 hypotheses about species richness patterns have likely been a topic of debate for so long because

422 several processes operating with different importance across the timeline of diversification are

423 capable of producing gradients (Etienne et al. 2019). It has been suggested that time for

424 speciation should be most detectable more immediately following broad-scale environmental

425 change, and when all regions are colonized, habitats that provide more opportunities for

426 speciation should over time become the most diverse (Pontarp and Wiens 2017). As diversity

427 increases, diversification rates slow as regions approach equilibrium (Brodie 2019). It follows

428 that the relative importance of evolutionary time and diversification rates as contributors to

429 biodiversity patterns varies with time with patterns ultimately affected by variation in ecological

430 limits (Rabosky and Hurlbert 2015; Pontarp and Wiens 2017; Storch et al. 2018).

432 Contemporary environmental change is our chance to explore pre-equilibrium processes. Cities

433 are the newest and most rapidly expanding biome, and it is clear that they have already

434 profoundly affected biodiversity patterns (Palumbi 2001; WWF 2018; Schmidt et al. 2020a). At

435 this early stage of colonization it is unlikely that urban communities have reached equilibrium,

436 suggesting processes related to evolutionary time and diversification will predominate until more

437 niches are occupied. Indeed, there is some evidence that following an initial extinction debt after 
438 rapid urbanization, older cities support higher species richness (Aronson et al. 2014). Human

439 disturbance had a negative effect on genetic diversity in our model, and also reduces gene flow

440 in mammals (Schmidt et al. 2020a). This suggests that there is potential for population

441 divergence and local adaptation if new urban niches are exploited and spatially varying selection

442 is sufficiently strong in cities. The extent to which urban populations adapt to local

443 environmental conditions is an ongoing and active field of study, and no consensus has been

444 reached (Lambert et al. 2021). Equilibrium levels of genetic diversity and species richness in

445 urban communities thus seem likely to strongly depend on resource availability and

446 heterogeneity both within and across cities, but these aspects of urban environments are not yet

447 well defined or understood (Norton et al. 2016; Des Roches et al. 2021a).

449 Notably, the negative correlation we find between spatial patterns of species richness and nuclear

450 genetic diversity runs opposite the relatively consistent positive correlations found between

451 species richness and mitochondrial genetic diversity gradients (Martin and McKay 2004; Adams

452 and Hadly 2012; Miraldo et al. 2016; Manel et al. 2020; Theodoridis et al. 2020). Mitochondrial

453 DNA has several idiosyncrasies associated with the specific biology of mitochondria that

454 distinguish it from genetic diversity measured with neutral nuclear DNA (Schmidt and Garroway

455 2021). The most commonly used mitochondrial markers are the protein-coding genes

456 cytochrome oxidase I and cytochrome b, which very likely do not evolve under neutrality

457 (Galtier et al. 2009). Unlike neutral nuclear DNA, mitochondrial genetic diversity is not

458 consistently related to life history, ecological traits, or census and effective population sizes

459 (Bazin et al. 2006; Nabholz et al. 2008; James and Eyre-Walker 2020). Mitochondrial genetic

460 diversity is thus a very different quantity than the neutral nuclear diversity estimates we use here, 
461 and its lack of relationship with population size makes it unsuited for testing hypotheses based

462 on ecological limits. Using genetic diversity metrics estimated from neutral nuclear DNA allows

463 us to more directly link environments to species richness through demography, population size,

464 and by extension, species life history traits which partly set the effective population size.

466 Ecosystem sustainability, given environmental perturbations occurring more frequently due to

467 human causes, depends on the resiliency of landscapes, communities, and populations (Oliver et

468 al. 2015). Our framework and the results presented herein suggest that we can understand

469 continental patterns of species richness and genetic diversity using two simple measures of

470 resource availability and heterogeneity. This is potentially informative for conservation practices

471 aiming to conserve both of these levels of biodiversity at once. Maps of neutral nuclear genetic

472 diversity can identify regions where long-term effective population sizes may have been

473 historically small, indicating areas where low levels of neutral genetic diversity are not

474 necessarily of immediate conservation concern (e.g., Yates et al. 2019). However, population

475 declines due to recent human disturbance in areas with historically low genetic diversity may

476 warrant specific attention. Furthermore, designing protected area networks based on species

477 richness to maintain beta diversity, or variation between sites (Bush et al. 2016; Socolar et al.

478 2016), will likely also capture differentiated populations with complementary genetic

479 compositions. The connections between environments, species richness, and genetic diversity we

480 find here suggest we should be able to make informed decisions for the joint conservation of

481 species and genetic diversity with knowledge of few environmental parameters. 
Author contributions: C.J.G. and C.S. conceptualized the study. C.S., S.D. and C.J.G. designed the study and C.S. conducted the statistical analysis with input from S.D. and C.J.G. All authors contributed to data interpretation. C.S. wrote the first draft of the manuscript and all authors participated in editing subsequent manuscript drafts.

Acknowledgements: We would like to thank the Population Ecology and Evolutionary Genetics group for their feedback on this manuscript. We are also grateful to the authors whose work provided the raw data for this synthesis. C.S. and C.J.G. were supported by a Natural Sciences and Engineering Research Council of Canada Discovery Grant to C.J.G. C.S. was also supported by a U. Manitoba Graduate Fellowship, and a U. Manitoba Graduate Enhancement of Tri-council

493 funding grant to C.J.G.

Data availability: Synthesized genetic data is available from the Dryad Data Repository (DOI: 10.5061/dryad.cz8w9gj0c). Species range boundary files and environmental data are available from open online sources (see Methods).

\section{References}

Adams, R. I., and E. A. Hadly. 2012. Genetic diversity within vertebrate species is greater at

Allouche, O., M. Kalyuzhny, G. Moreno-Rueda, M. Pizarro, and R. Kadmon. 2012. Areaheterogeneity tradeoff and the diversity of ecological communities. Proc. Natl. Acad. Sci. U. S. A. 109:17495-17500.

Alroy, J. 2009. Speciation and extinction in the fossil record of North American mammals. Pp. 301-323 in R. K. Butlin, J. R. Bridle, and D. Schluter, eds. Speciation and Patterns of Warren, N. S. G. Williams, S. Cilliers, B. Clarkson, C. Dobbs, R. Dolan, M. Hedblom, S. 
Klotz, J. L. Kooijmans, I. Kühn, I. MacGregor-Fors, M. McDonnell, U. Mörtberg, P. Pyšek, S. Siebert, J. Sushinsky, P. Werner, and M. Winter. 2014. A global analysis of the impacts of urbanization on bird and plant diversity reveals key anthropogenic drivers. Proc. R. Soc. B Biol. Sci. 281:20133330.

Bates, D., M. Mächler, B. Bolker, and S. Walker. 2015. Fitting linear mixed-effects models using

Bazin, E., S. Glémin, and N. Galtier. 2006. Population size does not influence mitochondrial

Bivand, R. S., E. Pebesma, and V. Gomez-Rubio. 2013. Applied spatial data analysis with R, genetic diversity in animals. Science (80-. ). 312:570-572. Second edition. Springer, NY.

Blanchet, G. F., P. Legendre, and Borcard. 2008. Forward selection of explanatory variables.

Borcard, D., and P. Legendre. 2002. All-scale spatial analysis of ecological data by means of principal coordinates of neighbour matrices. Ecol. Modell. 153:51-68.

Borcard, D., P. Legendre, C. Avois-Jacquet, and H. Tuomisto. 2004. Dissecting the spatial structure of ecological data at multiple scales. Ecology 85:1826-1832.

Brodie, J. F. 2019. Environmental limits to mammal diversity vary with latitude and global temperature. Ecol. Lett. 22:480-485.

Buffalo, V. 2021. Why do species get a thin slice of $\pi$ ? Revisiting Lewontin's Paradox of Variation. bioRxiv 2021.02.03.429633.

Bush, A., T. Harwood, A. J. Hoskins, K. Mokany, and S. Ferrier. 2016. Current Uses of Beta-

Ceballos, G., P. R. Ehrlich, A. D. Barnosky, A. García, R. M. Pringle, and T. M. Palmer. 2015.

CEC, NRCan/CCMEO, USGS, INEGI, CONABIO, and CONAFOR. 2010. 2010 North Accelerated modern human-induced species losses: Entering the sixth mass extinction. Sci. Adv. 1:e1400253. American Land Cover at $250 \mathrm{~m}$ spatial resolution.

Charlesworth, B., and D. Charlesworth. 2010. Elements of evolutionary genetics. Roberts \& Company Publishers, Greenwood Village, Colorado, USA.

CIESIN. 2016. Gridded Population of the World, Version 4 (GPWv4): Population Density. NASA Socioeconomic Data and Applications Center (SEDAC).

Corbett-Detig, R. B., D. L. Hartl, and T. B. Sackton. 2015. Natural Selection Constrains Neutral Diversity across A Wide Range of Species. PLoS Biol. 13:1-25.

Currie, D. J. 1991. Energy and large-scale patterns of animal- and plant-species richness. Am.

546 Des Roches, S., K. I. Brans, M. R. Lambert, L. R. Rivkin, A. M. Savage, C. J. Schell, C. Correa, 

J. Johnson, J. Munshi-South, E. P. Palkovacs, M. Szulkin, M. C. Urban, B. C. Verrelli, and M. Alberti. 2021a. Socio-eco-evolutionary dynamics in cities. Evol. Appl. 14:248-267.

Des Roches, S., L. H. Pendleton, B. Shapiro, and E. P. Palkovacs. 2021b. Conserving intraspecific variation for nature's contributions to people. Nat. Ecol. Evol., doi: 10.1038/s41559-021-01403-5.

Dray, S., G. Blanchet, D. Borcard, S. Clappe, G. Guenard, T. Jombart, G. Larocque, P. Legendre,

Epperson, B. K. 2005. Estimating dispersal from short distance spatial autocorrelation. Heredity N. Madi, and H. H. Wagner. 2017. adespatial: Multivariate Multiscale Spatial Analysis.

Dray, S., P. Legendre, and P. R. Peres-Neto. 2006. Spatial modelling: a comprehensive framework for principal coordinate analysis of neighbour matrices (PCNM). Ecol. Modell. 196:483-493.

Etienne, R. S., J. S. Cabral, O. Hagen, F. Hartig, A. H. Hurlbert, L. Pellissier, M. Pontarp, and D. Storch. 2019. A minimal model for the latitudinal diversity gradient suggests a dominant role for ecological limits. Am. Nat. 194:E122-E133.

Evanno, G., E. Castella, C. Antoine, G. Paillat, and J. Goudet. 2009. Parallel changes in genetic diversity and species diversity following a natural disturbance. Mol. Ecol. 18:1137-1144.

Fisher, J. B., R. J. Whittaker, and Y. Malhi. 2011. ET come home: Potential evapotranspiration in geographical ecology. Glob. Ecol. Biogeogr. 20:1-18.

Frankham, R. 1996. Relationship of Genetic Variation to Population Size in Wildlife. Conserv. Biol. 10:1500-1508.

Galtier, N., B. Nabholz, S. Glémin, and G. D. D. Hurst. 2009. Mitochondrial DNA as a marker of molecular diversity: A reappraisal. Mol. Ecol. 18:4541-4550.

Goudet, J., and T. Jombart. 2015. hierfstat: Estimation and Tests of Hierarchical F-Statistics.

Grimm, N. B., S. H. Faeth, N. E. Golubiewski, C. L. Redman, J. Wu, X. Bai, and J. M. Briggs. 2008. Global Change and the Ecology of Cities. Science (80-. ). 319:756-760.

Hewitt, G. M. 2000. The genetic legacy of the Quaternary ice ages. Nature 405:907-913.

Hubbell, S. P. 2001. The Unified Neutral Theory of Biodiversity and Biogeography. Princeton University Press, Princeton NJ.

IUCN. 2019. The IUCN Red List of Threatened Species. Version 2019-1.

James, J., and A. Eyre-Walker. 2020. Mitochondrial DNA sequence diversity in mammals: a correlation between the effective and census population sizes. Genome Biol. Evol., doi: 10.1093/gbe/evaa222.

Jiménez-Alfaro, B., M. Chytrý, L. Mucina, J. B. Grace, and M. Rejmánek. 2016. Disentangling vegetation diversity from climate-energy and habitat heterogeneity for explaining animal geographic patterns. Ecol. Evol. 6:1515-1526. 
Jones, K. E., J. Bielby, M. Cardillo, S. A. Fritz, J. O’Dell, C. D. L. Orme, K. Safi, W. Sechrest, E. H. Boakes, C. Carbone, C. Connolly, M. J. Cutts, J. K. Foster, R. Grenyer, M. Habib, C. A. Plaster, S. A. Price, E. A. Rigby, J. Rist, A. Teacher, O. R. P. Bininda-Emonds, J. L. Gittleman, G. M. Mace, and A. Purvis. 2009. PanTHERIA: a species-level database of life history, ecology, and geography of extant and recently extinct mammals. Ecology 90:26482648.

Jones, M. B., P. Slaughter, R. Nahf, C. Boettiger, C. Jones, J. Read, L. Walker, E. Hart, and S. Chamberlain. 2017. dataone: R Interface to the DataONE REST API.

Kadmon, R., and O. Allouche. 2007. Integrating the effects of area, isolation, and habitat heterogeneity on species diversity: A unification of island biogeography and niche theory. Am. Nat. 170:443-454.

Kerr, J. T., and L. Packer. 1997. Habitat heterogeneity as a determinant of mammal species richness. Nature 385:253-254.

Kimura, M. 1983. The Neutral Theory of Molecular Evolution. Cambridge University Press, Cambridge.

Kreft, H., and W. Jetz. 2007. Global patterns and determinants of vascular plant diversity. Proc. Natl. Acad. Sci. 104:5925-5930.

Lambert, M. R., K. I. Brans, S. Des Roches, C. M. Donihue, and S. E. Diamond. 2021. Adaptive Evolution in Cities: Progress and Misconceptions. Trends Ecol. Evol. 36:239-257. Elsevier Ltd.

Lefcheck, J., J. Byrnes, and J. Grace. 2019. piecewiseSEM: Piecewise Structural Equation Modeling.

Lefcheck, J. S. 2016. piecewiseSEM: Piecewise structural equation modelling in r for ecology, evolution, and systematics. Methods Ecol. Evol. 7:573-579.

Leigh, D. M., A. P. Hendry, E. Vázquez-Domínguez, and V. L. Friesen. 2019. Estimated six per cent loss of genetic variation in wild populations since the industrial revolution. Evol. Appl. 12:1505-1512.

Mackintosh, A., D. R. Laetsch, A. Hayward, B. Charlesworth, M. Waterfall, R. Vila, and K. Lohse. 2019. The determinants of genetic diversity in butterflies. Nat. Commun. 10:1-9.

Malécot, G. 1955. Decrease of relationship with distance. Cold Spring Harb. Symp. Quant. Biol. 20:52-53.

Manel, S., P. E. Guerin, D. Mouillot, S. Blanchet, L. Velez, C. Albouy, and L. Pellissier. 2020. Global determinants of freshwater and marine fish genetic diversity. Nat. Commun. 11:1-9. Springer US.

Martin, P. R., and J. K. McKay. 2004. Latitudinal variation in genetic divergence of populations and the potential for future speciation. Evolution (N. Y). 58:938-945.

McKinney, M. L. 2006. Urbanization as a major cause of biotic homogenization. Biol. Conserv. 127:247-260. 
Miraldo, A., S. Li, M. K. Borregaard, A. Florez-Rodriguez, S. Gopalakrishnan, M. Rizvanovic, Z. Wang, C. Rahbek, K. A. Marske, and D. Nogues-Bravo. 2016. An Anthropocene map of genetic diversity. Science (80-. ). 353:1532-1535.

Mittelbach, G. G., D. W. Schemske, H. V. Cornell, A. P. Allen, J. M. Brown, M. B. Bush, S. P. Harrison, A. H. Hurlbert, N. Knowlton, H. A. Lessios, C. M. McCain, A. R. McCune, L. A. McDade, M. A. McPeek, T. J. Near, T. D. Price, R. E. Ricklefs, K. Roy, D. F. Sax, D. Schluter, J. M. Sobel, and M. Turelli. 2007. Evolution and the latitudinal diversity gradient: Speciation, extinction and biogeography. Ecol. Lett. 10:315-331.

Mittell, E. A., S. Nakagawa, and J. D. Hadfield. 2015. Are molecular markers useful predictors of adaptive potential? Ecol. Lett. 18:772-778.

Nabholz, B., J. F. Mauffrey, E. Bazin, N. Galtier, and S. Glemin. 2008. Determination of mitochondrial genetic diversity in mammals. Genetics 178:351-361.

Nei, M. 1973. Analysis of gene diversity in subdivided populations. Proc. Natl. Acad. Sci. U. S. A. 70:3321-3323.

Norton, B. A., K. L. Evans, and P. H. Warren. 2016. Urban biodiversity and landscape ecology: patterns, processes and planning. Curr. Landsc. Ecol. Reports 1:178-192. Current Landscape Ecology Reports.

Oliver, T. H., M. S. Heard, N. J. B. Isaac, D. B. Roy, D. Procter, F. Eigenbrod, R. Freckleton, A. Hector, C. D. L. Orme, O. L. Petchey, V. Proença, D. Raffaelli, K. B. Suttle, G. M. Mace, B. Martín-López, B. A. Woodcock, and J. M. Bullock. 2015. Biodiversity and resilience of ecosystem functions. Trends Ecol. Evol. 30:673-684.

Palumbi, S. R. 2001. Humans as the world's greatest evolutionary force. Science (80-. ). 293:1786-1790.

Pontarp, M., L. Bunnefeld, J. S. Cabral, R. S. Etienne, S. A. Fritz, R. Gillespie, C. H. Graham, O. Hagen, F. Hartig, S. Huang, R. Jansson, O. Maliet, T. Münkemüller, L. Pellissier, T. F. Rangel, D. Storch, T. Wiegand, and A. H. Hurlbert. 2019. The latitudinal diversity gradient: novel understanding through mechanistic eco-evolutionary models. Trends Ecol. Evol. 34:211-223.

Pontarp, M., and J. J. Wiens. 2017. The origin of species richness patterns along environmental gradients: uniting explanations based on time, diversification rate and carrying capacity. J. Biogeogr. 44:722-735.

R Core Team. 2020. R: A Language and Environment for Statistical Computing. Vienna, Austria.

Rabosky, D. L., and A. H. Hurlbert. 2015. Species richness at continental scales is dominated by ecological limits. Am. Nat. 185:572-583.

Romiguier, J., P. Gayral, M. Ballenghien, A. Bernard, V. Cahais, A. Chenuil, Y. Chiari, R. Dernat, L. Duret, N. Faivre, E. Loire, J. M. Lourenco, B. Nabholz, C. Roux, G. Tsagkogeorga, A. A. T. Weber, L. A. Weinert, K. Belkhir, N. Bierne, S. Glémin, and N. Galtier. 2014. Comparative population genomics in animals uncovers the determinants of genetic diversity. Nature 515:261-263. 
Schmidt, C., M. Domaratzki, R. P. Kinnunen, J. Bowman, and C. J. Garroway. 2020a. Continentwide effects of urbanization on bird and mammal genetic diversity. Proc. R. Soc. B Biol. Sci. 287:20192497.

Schmidt, C., M. Domaratzki, R. P. Kinnunen, J. Bowman, and C. J. Garroway. 2020b. Data from: Continent-wide effects of urbanization on bird and mammal genetic diversity. Dryad Data Repository.

Schmidt, C., and C. J. Garroway. 2021. The conservation utility of mitochondrial genetic diversity in macrogenetic research. Conserv. Genet. 22:323-327.

Schmidt, C., J. Munshi-South, and C. J. Garroway. 2021. Determinants of genetic diversity and species richness of North American amphibians. bioRxiv 1-26.

Shipley, B. 2016. Cause and correlation in biology. 2nd ed. Cambridge University Press, Cambridge.

Simpson, G. G. 1964. Species density of North American recent mammals. Syst. Zool. 13:57-73.

Socolar, J. B., J. J. Gilroy, W. E. Kunin, and D. P. Edwards. 2016. How Should Beta-Diversity Inform Biodiversity Conservation? Trends Ecol. Evol. 31:67-80. Elsevier Ltd.

Sokal, R. R., and N. L. Oden. 1978. Spatial autocorrelation in biology 1. Methodology. Biol. J. Linn. Soc. 10:199-228.

Stein, A., K. Gerstner, and H. Kreft. 2014. Environmental heterogeneity as a universal driver of species richness across taxa, biomes and spatial scales. Ecol. Lett. 17:866-880.

Storch, D., E. Bohdalková, and J. Okie. 2018. The more-individuals hypothesis revisited: the role of community abundance in species richness regulation and the productivity-diversity relationship. Ecol. Lett. 21:920-937.

Theodoridis, S., D. A. Fordham, S. C. Brown, S. Li, C. Rahbek, and D. Nogues-Bravo. 2020. Evolutionary history and past climate change shape the distribution of genetic diversity in terrestrial mammals. Nat. Commun. 11:2557.

Trabucco, A., and R. Zomer. 2019. Global Aridity Index and Potential Evapotranspiration (ET0) Climate Database v2. , doi: 10.6084/m9.figshare.7504448.v3.

Vellend, M. 2005. Species diversity and genetic diversity: parallel processes and correlated patterns. Am. Nat. 166:199-215.

Weir, B. S., and J. Goudet. 2017. A unified characterization of population structure. Genetics 206:2085-2103.

Worm, B., and D. P. Tittensor. 2018. A theory of global biodiversity. Princeton University Press, Princeton, New Jersey.

Wright, D. H. 1983. Species-Energy Theory: An Extension of Species-Area Theory. Oikos 41:496-506.

WWF. 2018. Living Planet Report - 2018: Aiming higher. WWF, Gland, Switzerland.

Yates, M. C., E. Bowles, and D. J. Fraser. 2019. Small population size and low genomic 
bioRxiv preprint doi: https://doi.org/10.1101/2020.06.03.132092; this version posted June 4, 2021. The copyright holder for this preprint (which was not certified by peer review) is the author/funder. All rights reserved. No reuse allowed without permission.

diversity have no effect on fitness in experimental translocations of a wild fish. Proc. R.

700

Soc. B Biol. Sci. 286.

701 
Table 1. Data summary. Summary of aggregated raw genetic data: mean gene diversity, mean number of loci, median number of individuals at sites per species. Species mass $(\mathrm{kg})$; species richness $=$ mean species richness at sites; energy $=$ mean potential evapotranspiration across species' ranges $(\mathrm{mm} / \mathrm{yr})$, heterogeneity = mean land cover diversity (Simpson's Index) within a 5,000 km² zone around a site; human population = mean human population density across sites. Ranges of values are given in parentheses for

706 species with multiple sample sites.

Species (\# sites)
Alces alces (2)
Antilocapra americana (1)
Bison bison (8)
Canis latrans (41)
Canis lupus (1)
Glaucomys volans (8)
Lasionycteris noctivagans (1)
Lasiurus cinereus (1)
Leopardus pardalis (2)
Lepus americanus (39)
Lynx canadensis (33)
Lynx rufus (65)
Martes americana (29)
Mephitis mephitis (1)
Microdipodops megacephalus (3)
Microdipodops pallidus (2)
Myotis lucifugus (65)
Myotis septentrionalis (15)
Odocoileus hemionus (67)
Odocoileus virginianus (64)
Oreamnos americanus (1)
Otospermophilus beecheyi (3)
Ovis canadensis (16)
Pekania pennanti (34)
(3)

\begin{tabular}{|c|c|c|c|}
\hline Gene diversity & \# loci & \# Individuals & Mass \\
\hline $0.47(0.43-0.51)$ & 10 & 44.5 (40-49) & 481 \\
\hline 0.67 & 19 & 175 & 46.9 \\
\hline $0.47(0.43-0.51)$ & 29 & $26.5(7-31)$ & 620 \\
\hline $0.77(0.69-0.82)$ & 10 & $7(5-10)$ & 12 \\
\hline 0.66 & 12 & 62 & 35 \\
\hline $0.75(0.65-0.81)$ & 7 & $18.5(6-120)$ & 0.07 \\
\hline 0.83 & 18 & 87 & 0.01 \\
\hline 0.88 & 19 & 132 & 0.03 \\
\hline $0.47(0.36-0.58)$ & 10 & $35(28-42)$ & 11.9 \\
\hline $0.66(0.48-0.76)$ & 8 & $15(7-100)$ & 1.57 \\
\hline $0.72(0.46-0.75)$ & $14.15(14-15)$ & $26(13-328)$ & 9.77 \\
\hline $0.73(0.56-0.79)$ & $14.37(9-17)$ & $27(7-141)$ & 6.39 \\
\hline $0.63(0.54-0.67)$ & 12 & $22(11-47)$ & 0.88 \\
\hline 0.81 & 9 & 345 & 2.4 \\
\hline $0.78(0.73-0.82)$ & 11 & $62(49-69)$ & 0.01 \\
\hline $0.73(0.73-0.73)$ & 10 & $52.5(42-63)$ & 0.01 \\
\hline $0.83(0.72-0.9)$ & $9.2(8-11)$ & 33 (11-167) & 0.01 \\
\hline $0.87(0.85-0.88)$ & 5 & $54(34-110)$ & 0.01 \\
\hline $0.62(0.2-0.72)$ & $10.55(10-18)$ & $29(7-262)$ & 83.8 \\
\hline $0.81(0.76-0.84)$ & 14 & $32.5(10-79)$ & 75 \\
\hline 0.52 & 22 & 102 & 71.3 \\
\hline $0.75(0.72-0.78)$ & 11 & $61(40-104)$ & 0.6 \\
\hline $0.61(0.48-0.67)$ & $40.12(16-210)$ & $42.5(10-276)$ & 74.6 \\
\hline $0.62(0.52-0.66)$ & 16 & $20.5(7-48)$ & 3.75 \\
\hline
\end{tabular}

\begin{tabular}{|c|c|c|}
\hline $\begin{array}{l}\text { Species } \\
\text { richness }\end{array}$ & Energy & Heterogeneity \\
\hline $34.5(34-35)$ & 694.5 & $0.81(0.78-0.84)$ \\
\hline 63 & 1615.39 & 0.73 \\
\hline 47.62 (32-69) & 745.94 & $0.68(0.4-0.82)$ \\
\hline $48.39(40-55)$ & 1039.97 & $0.7(0.27-0.85)$ \\
\hline 44 & 642.5 & 0.78 \\
\hline $49.12(47-51)$ & 1287.09 & $0.68(0.58-0.8)$ \\
\hline 53 & 1252.72 & 0.71 \\
\hline 53 & 1126.83 & 0.71 \\
\hline $51(49-53)$ & 2287.6 & $0.77(0.76-0.77)$ \\
\hline $50.44(2-73)$ & 750.2 & $0.65(0.27-0.81)$ \\
\hline $43.82(6-50)$ & 655.47 & $0.73(0.61-0.81)$ \\
\hline $55.6(33-81)$ & 1459.73 & $0.62(0.19-0.83)$ \\
\hline $45.86(42-50)$ & 709.47 & $0.73(0.65-0.79)$ \\
\hline 53 & 1230.39 & 0.73 \\
\hline $64.33(59-70)$ & 1780.52 & $0.45(0.37-0.56)$ \\
\hline $59(58-60)$ & 2045.67 & $0.25(0.24-0.27)$ \\
\hline $44.45(32-66)$ & 971.21 & $0.75(0.21-0.86)$ \\
\hline $42.13(41-43)$ & 952.73 & $0.82(0.74-0.85)$ \\
\hline $57.72(2-87)$ & 1356.11 & $0.61(0.08-0.84)$ \\
\hline $48.95(46-52)$ & 1243.86 & $0.55(0.32-0.74)$ \\
\hline 37 & 743.39 & 0.79 \\
\hline 64.33 (57-69) & 1634.31 & $0.6(0.54-0.71)$ \\
\hline $49.5(44-63)$ & 1553.5 & $0.38(0.15-0.73)$ \\
\hline $45.56(3-51)$ & 808.85 & $0.65(0.25-0.8)$ \\
\hline
\end{tabular}

Human population

$134.79(1.45-268.14)$

3.42

$1.3(0.52-3.42)$

134.92 (1.54-1463.37)

5.85

7.31 (1.04-33.59)

27.12 (18.73-35.51)

79.95 (0.69-2711.29)

4.59 (1.04-56.48)

189.69 (1.04-3540.4)

$1.21(0.69-2.27)$

34.19

1.04 (1.04-1.04)

1.04 (1.04-1.04)

$25.96(0-493.88)$

16.05 (1.04-123.03)

$36.97(0.83-1213.54)$

$57.42(6.13-351.21)$

2.06

$6.18(3.08-9.03)$

$1.27(1.04-3.42)$

130.82 (0-2620) 
Peromyscus leucopus (36)

Peromyscus maniculatus (10)

Procyon lotor (1)

Puma concolor (13)

Rangifer tarandus (82)

Sylvilagus transitionalis (3)

Tamiasciurus douglasii (14)

Tamiasciurus hudsonicus (12)

Taxidea taxus (12)

Ursus americanus (43)

Ursus arctos (19)

Ursus maritimus (35)

Vulpes lagopus (3)

Vulpes vulpes (16)

$\begin{array}{rr}0.82(0.75-0.87) & 13.19(10-18) \\ 0.77(0.75-0.8) & 10.9(10-11) \\ 0.84 & 10 \\ 0.48(0.33-0.58) & 33.62(10-46) \\ 0.77(0.45-0.87) & 16.96(14-21) \\ 0.42(0.32-0.47) & 10 \\ 0.65(0.58-0.72) & 9 \\ 0.66(0.48-0.77) & 9 \\ 0.73(0.43-0.82) & 17.33(12-20) \\ 0.72(0.32-0.82) & 15(8-20) \\ 0.67(0.51-0.77) & 9.89(8-20) \\ 0.69(0.56-0.8) & 15.09(8-24) \\ 0.72(0.68-0.78) & 9 \\ 0.65(0.53-0.74) & 11.44(8-13)\end{array}$

$\begin{array}{rrr}20(5-38) & 0.02 & 44.83(12-53) \\ 12.5(6-31) & 0.02 & 48.3(47-51) \\ 330 & 6.37 & 51 \\ 51(21-739) & 53.9 & 61.77(50-82) \\ 24(5-283) & 108 & 40.26(5-63) \\ 48(6-103) & 0.81 & 50.33(50-51) \\ 10.5(7-24) & 0.22 & 65(54-70) \\ 11(5-48) & 0.2 & 62.58(54-68) \\ 34.5(19-649) & 7.84 & 49.25(39-56) \\ 18(5-2444) & 111 & 51.35(0-86) \\ 48(14-729) & 196 & 36.68(1-68) \\ 31(6-1050) & 375 & 9.17(2-33) \\ 28(8-42) & 3.6 & 25(22-27) \\ 30(9-116) & 4.84 & 44.81(24-54)\end{array}$

1

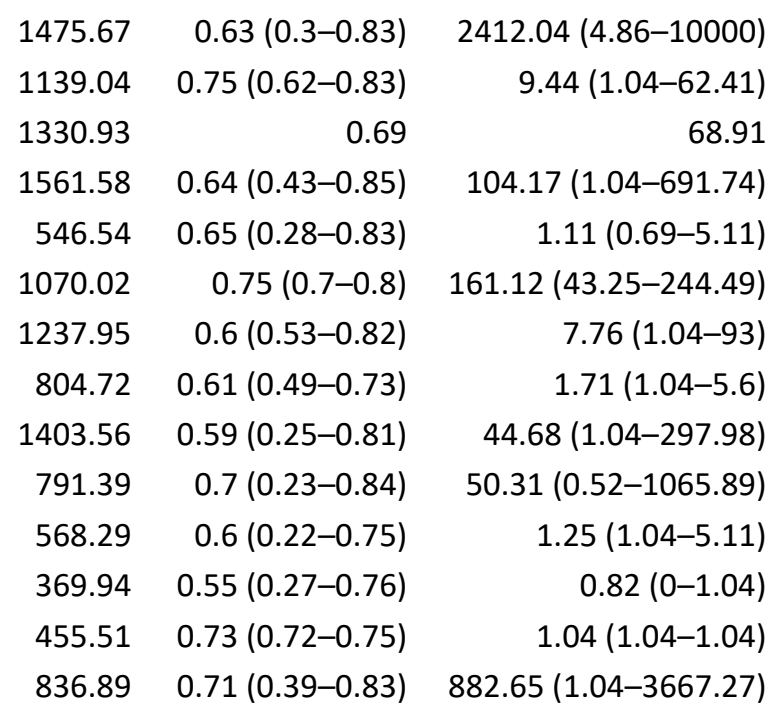

$0.71(0.39-0.83)$

$2412.04(4.86-10000)$

$9.44(1.04-62.41)$

68.91

$104.17(1.04-691.74)$

$1.11(0.69-5.11)$

$161.12(43.25-244.49)$

$7.76(1.04-93)$

$1.71(1.04-5.6)$

44.68 (1.04-297.98)

$50.31(0.52-1065.89)$

$1.25(1.04-5.11)$

$0.82(0-1.04)$

$1.04(1.04-1.04)$

$882.65(1.04-3667.27)$ 


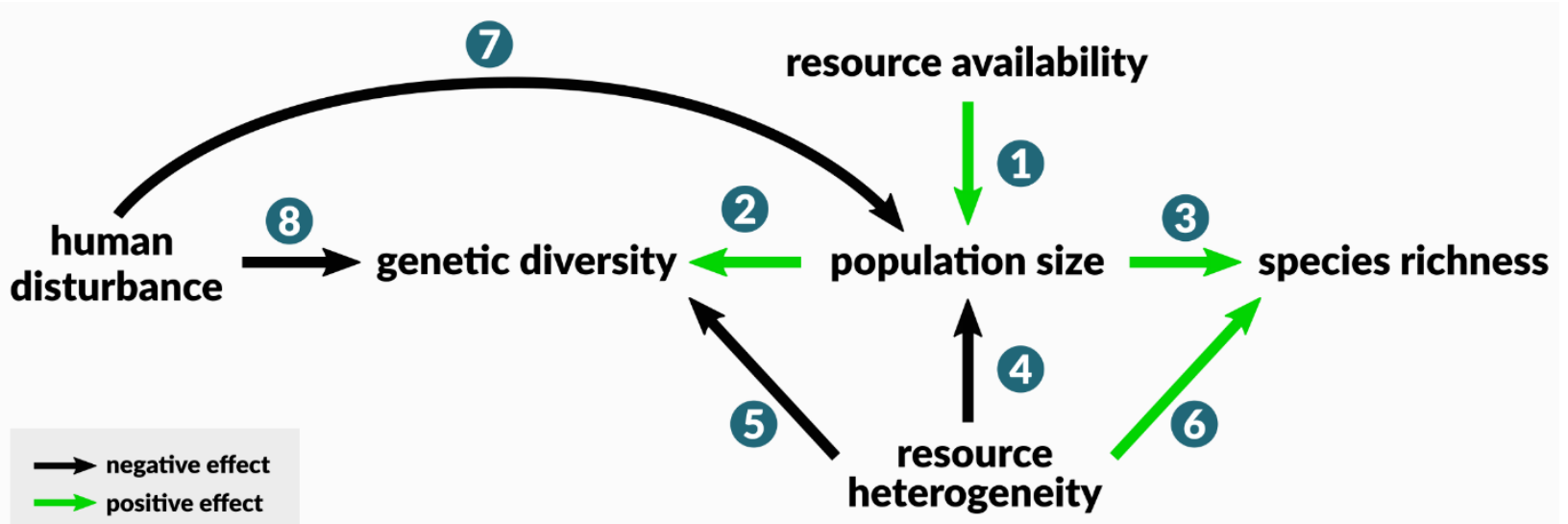

709 Fig. 1. Framework integrating genetic diversity into ecological limits hypotheses. We focus on

710 two major ecological limits pathways which stem from resource availability (the more

711 individuals hypothesis) and resource heterogeneity. Under the more individuals hypothesis,

712 resource availability across a species range positively affects species' long-term effective

713 population sizes (1). Nuclear genetic diversity increases with the effective population size (2). If

714 population size is regulated by resource availability, it will be positively associated with

715 community size and thus species richness (3). In heterogeneous environments, populations and

716 species specialize to different niches but have smaller population sizes (4). Specialization

717 reduces gene flow (5) and enhances species' ability to coexist (6). Human land transformation

718 reduces wildlife habitat (7) and gene flow among populations (8). 


\section{Data synthesis}

Neutral microsatellite data (e.g., DRYAD)

38 species

801 sites

Genetic diversity = gene diversity

\section{North American}

landcover (CEC)

Heterogeneity = land cover diversity

(Simpson's Index)

\section{Analysis pipeline}

\section{Broad spatial pattern in genetic diversity?}

Distance-based Moran's eigenvector maps

\section{YES}

Visible longitudinal pattern opposite of species richness; $24 \%$ of variation is spatial

\section{Species range maps (IUCN)}

\section{North American}

terrestrial mammals

\section{Species richness $=$}

\# overlapping ranges

\section{Body size data}

(PanTHERIA)

\section{Long-term effective \\ population size $=$ adult mass*}

721 Fig. 2. Methodological workflow detailing data sources and our series of analyses. For structural

722 equation models, variables were either measured at each of 801 sample sites for which genetic

723 diversity data was available, or at the species level ( $n=38$ species). 

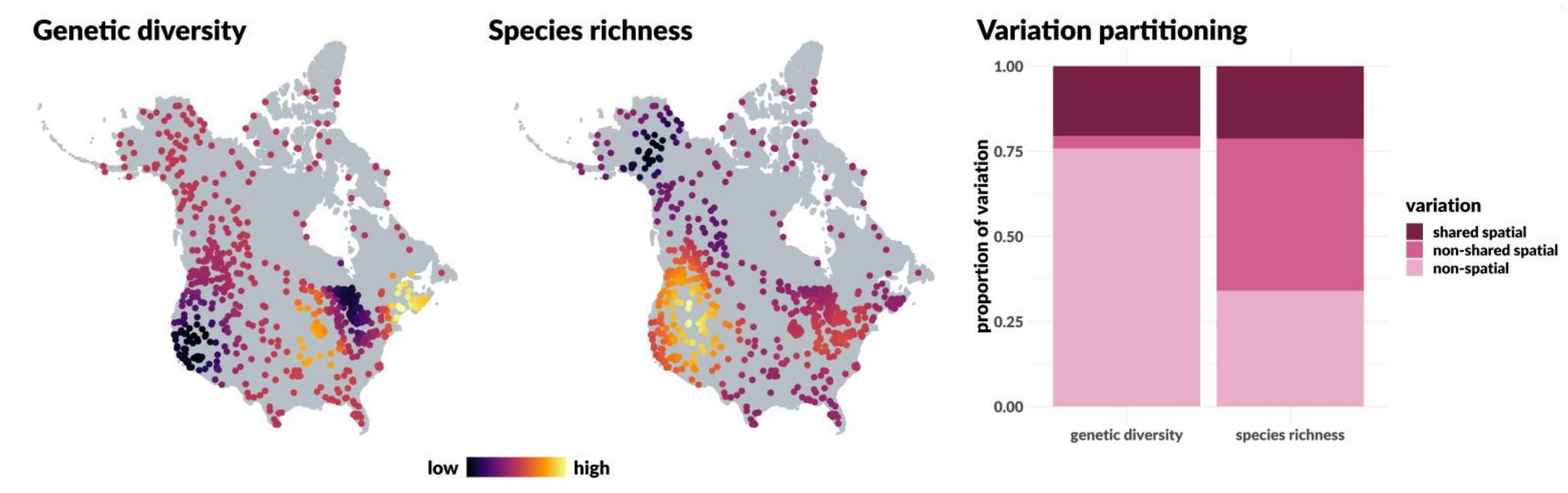

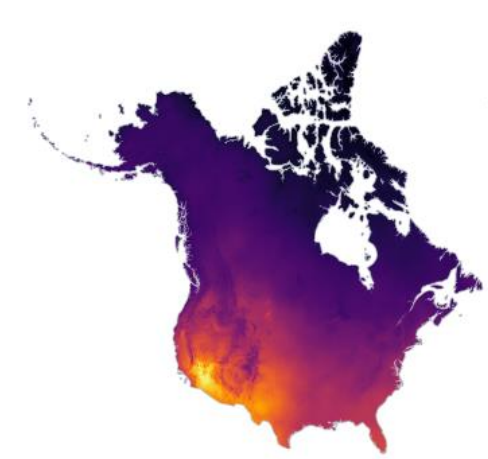

Energy (potential evapotranspiration)

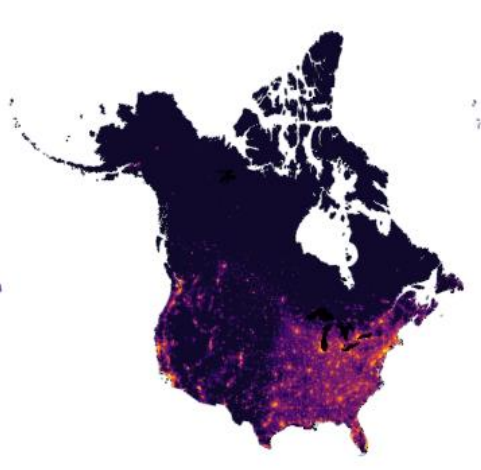

Human population density

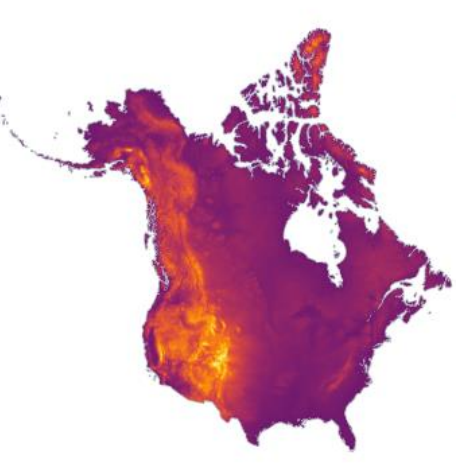

Elevation

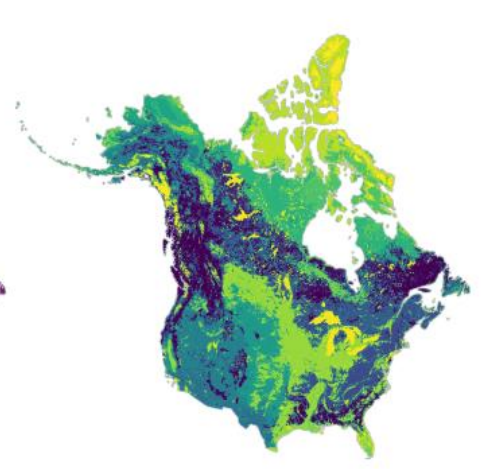

Land cover type

Fig. 3. Spatial patterns of biodiversity and environmental factors. (Top row) Locations of 801 North American mammal populations for which raw microsatellite data was available in public repositories. Point color indicates predicted values of genetic diversity and species richness based on spatial patterns detected in the data. The variation partitioning plot shows the proportion of variation in genetic diversity and species richness which can be explained by spatial factors. Spatial variation is further broken down into shared 
and non-shared spatial variation. (Bottom row) Major environmental features of North America. Note land cover is categorical and colors represent different types. Elevation is shown for reference, but was not included in our models. 
A

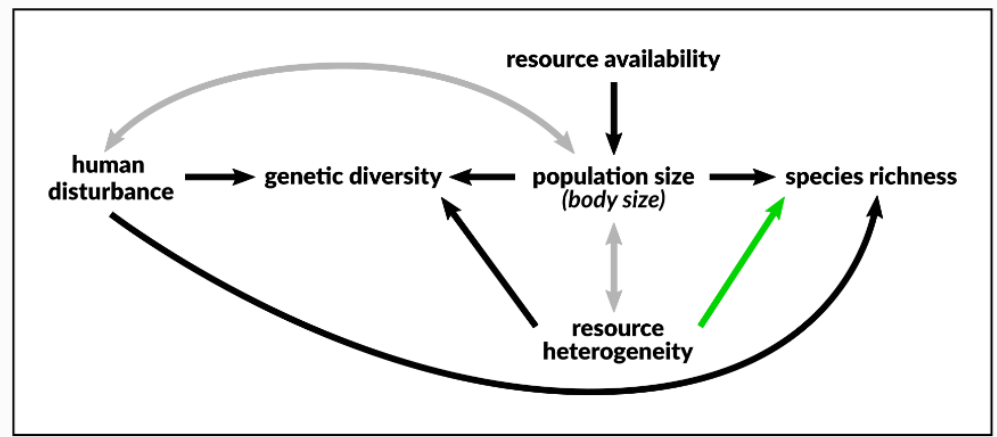

B

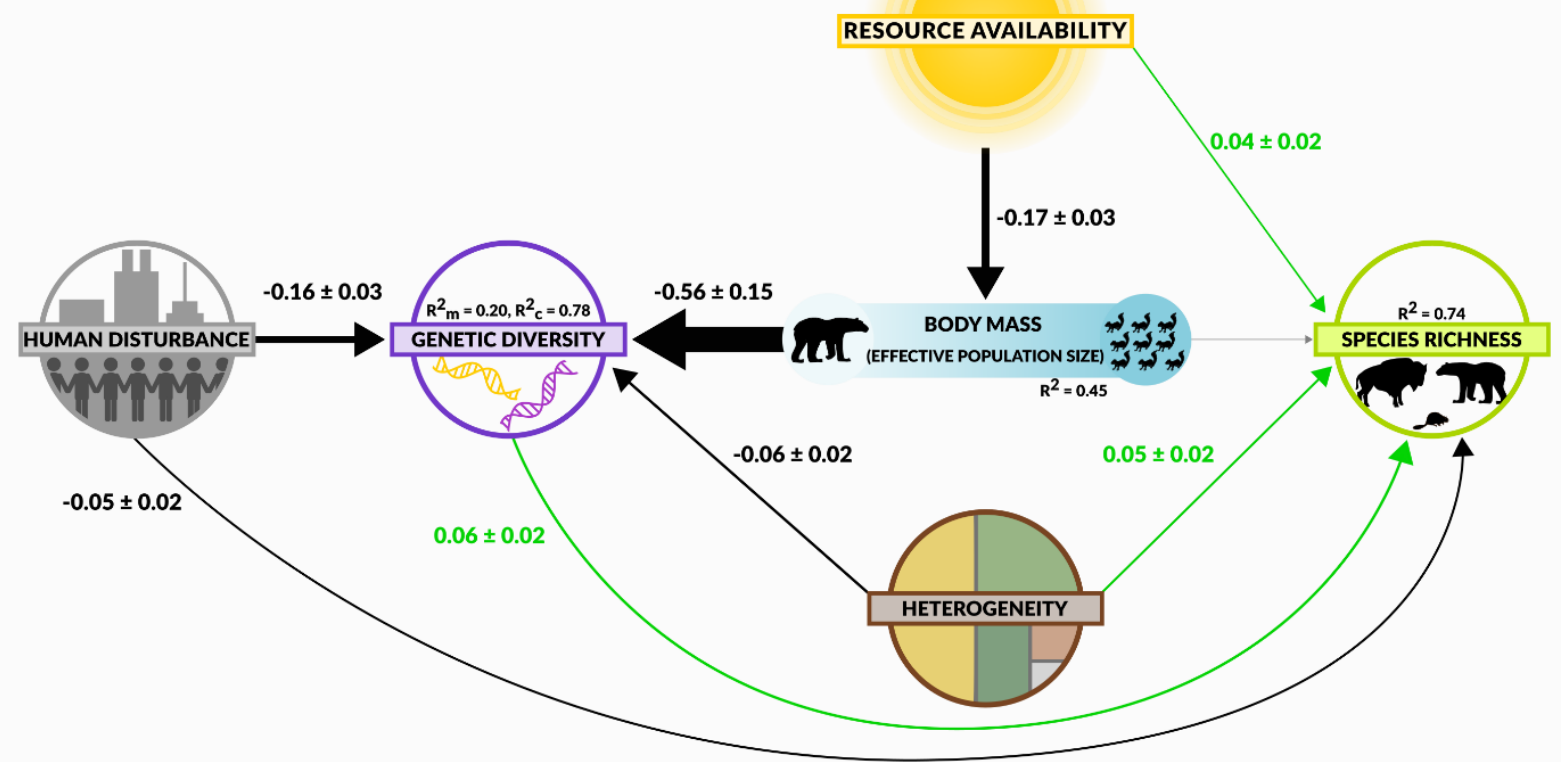

Fig. 4. Structural equation models. (a) Our conceptual hypothesis network, modified from Figure 1 to accommodate variables measured at species and site levels. Single-headed arrows represent unidirectional relationships between variables. Grey double-headed arrows indicate variables with correlated errors that were excluded from model evaluation (see Methods). (b) Structural equation model results. Green and black lines are positive and negative relationships, respectively, and the grey line is an unsupported link. Line widths reflect partial regression coefficients, which are listed for each path with standard errors. $R^{2}$ values are the amount of variation explained for each response variable. Genetic diversity was fit with a random effect for species: $R^{2}{ }_{m}$ is the variation explained by fixed effects only, and $R^{2}{ }_{c}$ is the variation explained by fixed and random effects. 
Supplementary Information for: Genetic and species-level biodiversity patterns are linked by demography and ecological opportunity

\section{Includes:}

Figures S1-S3

Tables S1-S5 


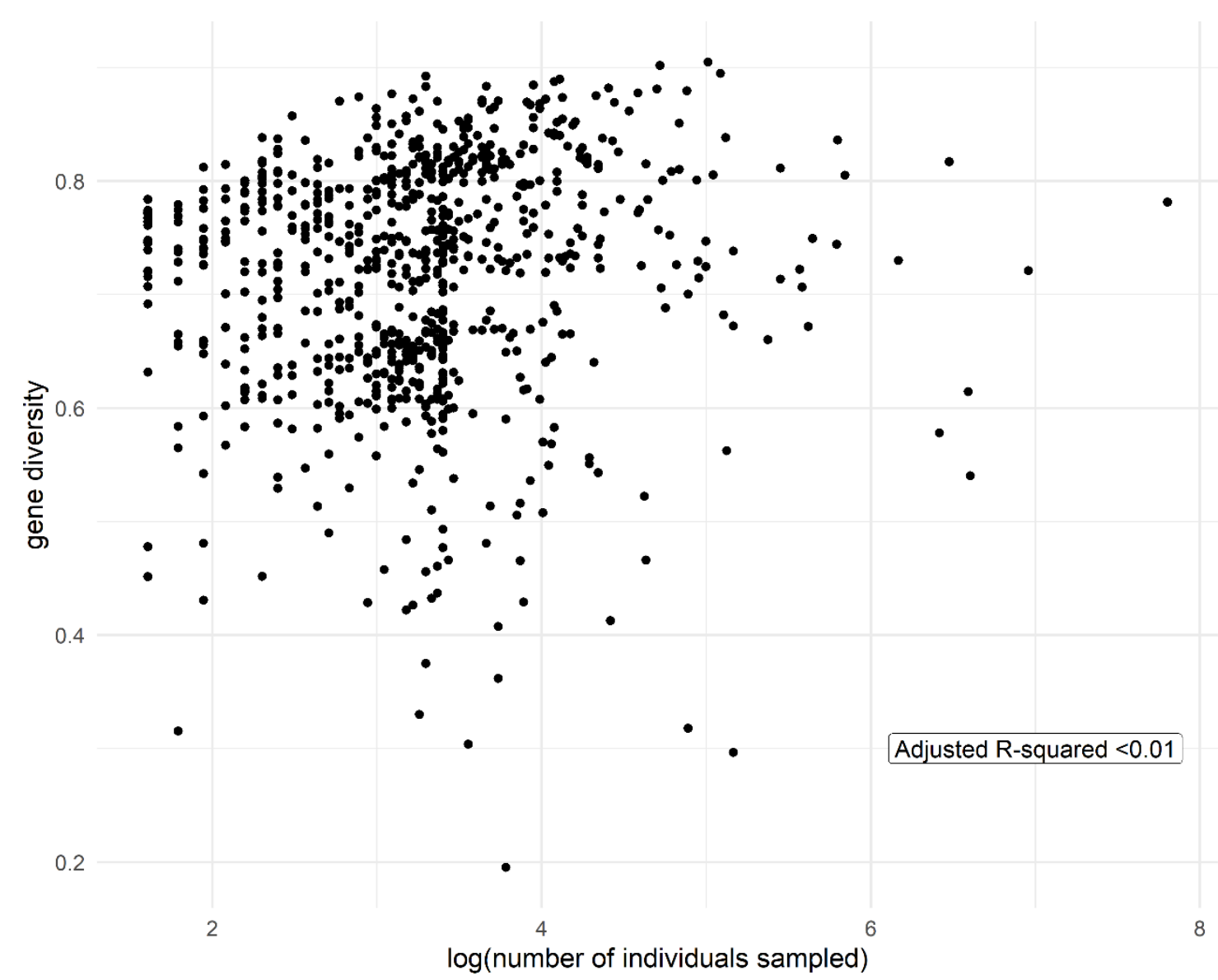

Figure S1. Plot of gene diversity vs. sample size. Gene diversity as a metric of genetic diversity depends on allele frequencies and is minimally affected by sample size. Larger populations have more rare alleles, which contribute little to gene diversity. 


\section{Genetic diversity (raw data)}

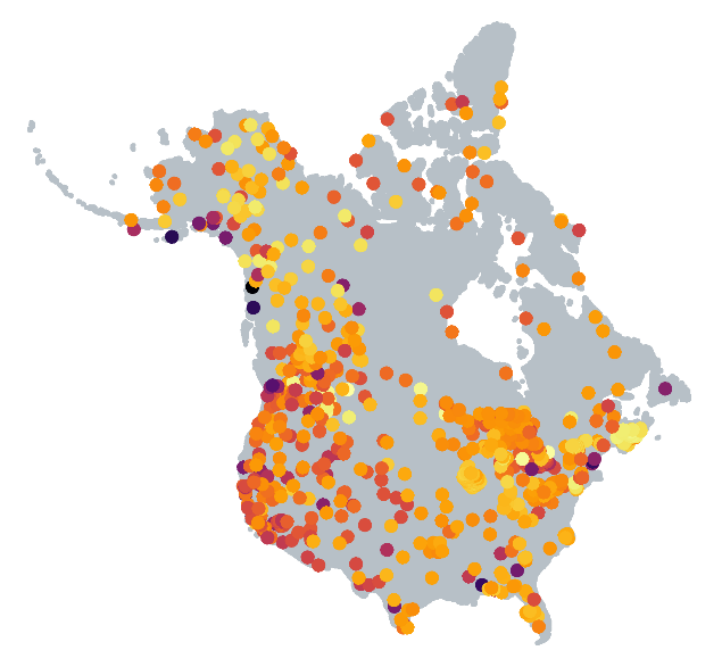

\section{Species richness (raw data)}

0.8

0.6

0.4

0.4

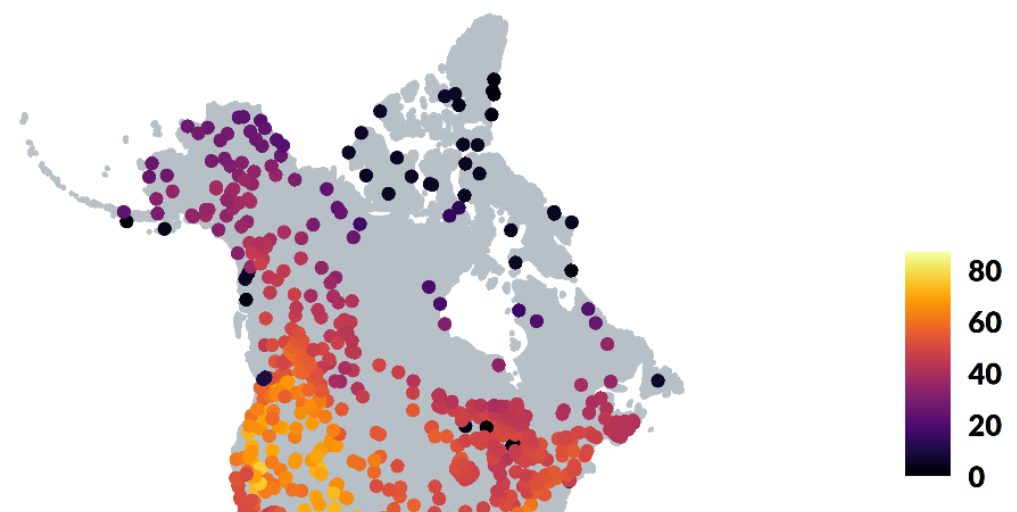

Figure S2. Maps of raw genetic diversity (gene diversity) and species richness data for each site. Clear gradients are visible in species richness but not genetic diversity. This is because most (65\%) variation in species richness was spatial, in contrast to genetic diversity where comparatively less (24\%) variation was spatially structured (Fig. 3 ). 

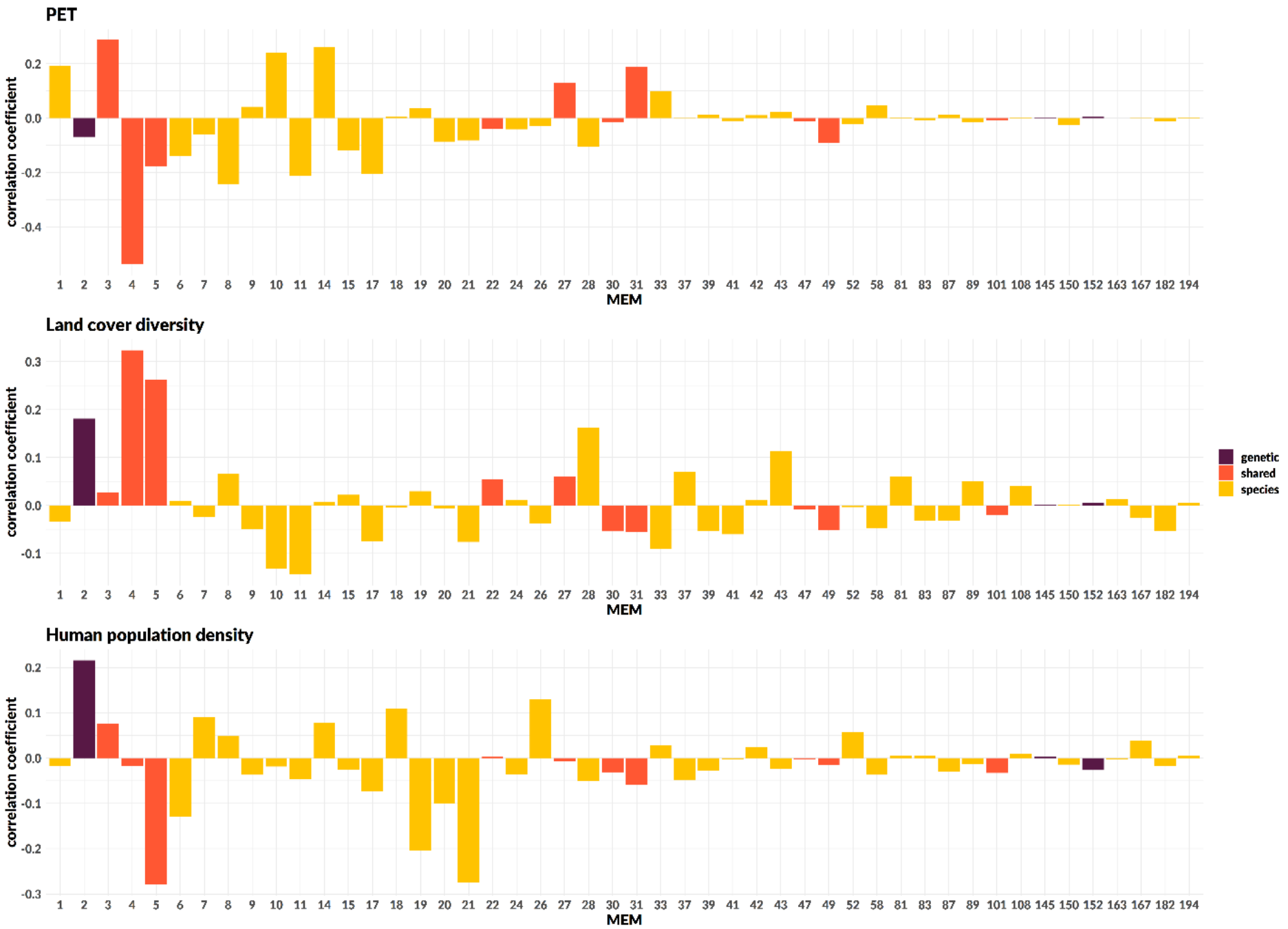

Figure S3. Correlation coefficients for spatial patterns (MEMs) and environmental variables measured at the site level: potential evapotranspiration (PET), land cover diversity, and human population density. MEMs describe spatial patterns in genetic diversity, species richness, or both (shared spatial patterns). MEMs are ordered from broad (MEM1) to fine scale (MEM194) patterns. Strong correlations indicate that environmental variables included in structural equation models account for broad scale spatial patterns present in genetic diversity and species richness. 
1 Table S1. Path coefficients and standard errors for structural equation model presented in main

2 text (Fisher's $\mathrm{C}=2.25, p=0.33,2$ degrees of freedom). Heterogeneity is measured within 5000

$3 \mathrm{~km}^{2}$ of a site.

\begin{tabular}{|c|c|c|}
\hline Response & Predictor & Estimate $\pm \mathrm{SE}$ \\
\hline genetic diversity & human population density & $-0.16 \pm 0.03$ \\
\hline genetic diversity & body size & $-0.56 \pm 0.15$ \\
\hline genetic diversity & heterogeneity & $-0.06 \pm 0.02$ \\
\hline body size & PET & $-0.17 \pm 0.03$ \\
\hline species richness & body size & $0.02 \pm 0.02$ \\
\hline species richness & heterogeneity & $0.05 \pm 0.02$ \\
\hline species richness & human population density & $-0.05 \pm 0.02$ \\
\hline species richness & PET & $0.04 \pm 0.02$ \\
\hline species richness & genetic diversity & $0.06 \pm 0.02$ \\
\hline Correlated errors & & Partial correlation coefficient \\
\hline body size & human population density & $0.10 *$ \\
\hline body size & heterogeneity & -0.02 \\
\hline
\end{tabular}


5 Table S2. Path coefficients and standard errors for structural equation model; heterogeneity is

6 measured within $20000 \mathrm{~km}^{2}$ of a site (Fisher's $\mathrm{C}=2.09, p=0.35,2$ degrees of freedom).

\begin{tabular}{|c|c|c|}
\hline Response & Predictor & Estimate $\pm \mathrm{SE}$ \\
\hline genetic diversity & human population density & $-0.16 \pm 0.03$ \\
\hline genetic diversity & body size & $-0.57 \pm 0.15$ \\
\hline genetic diversity & heterogeneity & $-0.04 \pm 0.03$ \\
\hline body size & PET & $-0.17 \pm 0.03$ \\
\hline species richness & body size & $0.02 \pm 0.02$ \\
\hline species richness & heterogeneity & $0.06 \pm 0.02$ \\
\hline species richness & human population density & $-0.05 \pm 0.02$ \\
\hline species richness & PET & $0.05 \pm 0.02$ \\
\hline species richness & genetic diversity & $0.06 \pm 0.02$ \\
\hline Correlated errors & & Partial correlation coefficient \\
\hline body size & human population density & $0.10 *$ \\
\hline body size & heterogeneity & -0.03 \\
\hline
\end{tabular}


8 Table S3. Path coefficients and standard errors for structural equation model; heterogeneity is

9 measured within $50000 \mathrm{~km}^{2}$ of a site (Fisher's $\mathrm{C}=1.78, p=0.41,2$ degrees of freedom).

\begin{tabular}{|c|c|c|}
\hline Response & Predictor & Estimate $\pm \mathrm{SE}$ \\
\hline genetic diversity & human population density & $-0.17 \pm 0.03$ \\
\hline genetic diversity & body size & $-0.57 \pm 0.15$ \\
\hline genetic diversity & heterogeneity & $0.00 \pm 0.03$ \\
\hline body size & PET & $-0.17 \pm 0.03$ \\
\hline species richness & body size & $0.02 \pm 0.02$ \\
\hline species richness & heterogeneity & $0.06 \pm 0.02$ \\
\hline species richness & human population density & $-0.06 \pm 0.02$ \\
\hline species richness & PET & $0.05 \pm 0.02$ \\
\hline species richness & genetic diversity & $0.06 \pm 0.02$ \\
\hline Correlated errors & & Partial correlation coefficient \\
\hline body size & human population density & $0.10 *$ \\
\hline body size & heterogeneity & -0.03 \\
\hline
\end{tabular}


12 Table S4. Path coefficients and standard errors for structural equation model; heterogeneity is

13 measured within $100000 \mathrm{~km}^{2}$ of a site (Fisher's $\mathrm{C}=1.54, p=0.46,2$ degrees of freedom).

\begin{tabular}{|c|c|c|}
\hline Response & Predictor & Estimate $\pm \mathrm{SE}$ \\
\hline genetic diversity & human population density & $-0.18 \pm 0.03$ \\
\hline genetic diversity & body size & $-0.56 \pm 0.15$ \\
\hline genetic diversity & heterogeneity & $0.04 \pm 0.03$ \\
\hline body size & PET & $-0.17 \pm 0.03$ \\
\hline species richness & body size & $0.02 \pm 0.02$ \\
\hline species richness & heterogeneity & $0.05 \pm 0.02$ \\
\hline species richness & human population density & $-0.05 \pm 0.02$ \\
\hline species richness & PET & $0.04 \pm 0.02$ \\
\hline species richness & genetic diversity & $0.06 \pm 0.02$ \\
\hline Correlated errors & & Partial correlation coefficient \\
\hline body size & human population density & $0.10^{*}$ \\
\hline body size & heterogeneity & -0.03 \\
\hline
\end{tabular}


16 Table S5. Path coefficients and standard errors for structural equation model using actual

17 evapotranspiration (AET) as a measure of resource availability. Heterogeneity is measured

18 within $5000 \mathrm{~km}^{2}$ of a site (Fisher's $\mathrm{C}=0.53, p=0.77,2$ degrees of freedom). Genetic diversity

$19 \quad \mathrm{R}_{\mathrm{m}}^{2}=0.20 ; \mathrm{R}_{\mathrm{c}}^{2}=0.78$; body size $\mathrm{R}^{2}=0.48$; species richness $\mathrm{R}^{2}=0.74$.

\begin{tabular}{llc} 
Response & Predictor & Estimate \pm SE \\
\hline genetic diversity & human population density & $-0.16 \pm 0.03$ \\
genetic diversity & body size & $-0.56 \pm 0.15$ \\
genetic diversity & heterogeneity & $-0.06 \pm 0.02$ \\
body size & AET & $-0.33 \pm 0.03$ \\
species richness & body size & $0.03 \pm 0.02$ \\
species richness & heterogeneity & $0.04 \pm 0.02$ \\
species richness & human population density & $-0.05 \pm 0.02$ \\
& & $0.05 \pm 0.02$ \\
species richness & AET & $0.05 \pm 0.02$ \\
species richness & genetic diversity & \\
& &
\end{tabular}

